\title{
Grupos minoritários, grupos vulneráveis e o problema da (in)tolerância: uma relação linguístico-discursiva e ideológica entre o desrespeito e a manifestação do ódio no contexto brasileiro
}

[ Minority groups, vulnerable groups and the problem of (in)tolerance: a linguistic-discursive and ideological relationship between disrespect and the manifestation of hatred in the Brazilian context

\section{Cláudio Márcio do Carmo}

RESUMO - O presente artigo consiste numa reflexão que parte do domínio conceitual do que se pode compreender por grupos minoritários (ou minorias) e grupos vulneráveis, no que tange a duas problemáticas: a primeira diz respeito ao que se entende por (in)tolerância, e a outra, às questões ideológicas que perpassam um discurso que tem se tornado cada vez mais comum no Brasil, o discurso de ódio, com desdobramentos na esfera comportamental que não condizem nem com os ideais democráticos nem com o respeito à dignidade humana. PALAVRAS-CHAVE - grupos minoritários; grupos vulneráveis; (in)tolerância, discurso de ódio; Brasil. ABSTRACT - This article is a reflection developed on the conceptual domain about what can be understood by minority groups (or minorities) and vulnerable groups, concerning two issues, being the first what is meant by (in)tolerance and the other about the ideological issues that underlie a discourse that has become increasingly common in Brazil: the hate discourse, with impacts on the behavioral sphere that are not consistent either with the democratic ideals nor with the respect for human dignity. KEYWORDS · minority groups; vulnerable groups; (in)tolerance; hate discourse; Brazil.

Recebido em 24 de novembro de 2015

Aprovado em 28 de março de 2016

CARMO, Cláudio Márcio do. Grupos minoritários, grupos vulneráveis e o problema da (in)tolerância: uma relação linguístico-discursiva e ideológica entre o desrespeito e a manifestação do ódio no contexto brasileiro. Revista do Instituto de Estudos Brasileiros, Brasil, n. 64, p. 20I-223, ago. 2016.

DOI: http://dx.doi.org/Io.II6o6/issn.23I6-90IX.voi64p20I-223

I Universidade Federal de São João del-Rei (UFSJ, São João del-Rei, MG, Brasil). 


\section{INTRODUÇÃO}

O presente artigo consiste numa reflexão que parte do domínio conceitual do que se pode compreender por grupos minoritários ou minorias e grupos vulneráveis, no que tange a duas problemáticas: a primeira diz respeito ao que se entende por (in) tolerância, e a outra, às questões ideológicas que perpassam um discurso que tem se tornado cada vez mais comum no Brasil, o discurso de ódio, com desdobramentos na esfera da ação, seja como desrespeito, seja como comportamento odioso.

É importante ressaltar que nossa pretensão não é fazer uma análise microlinguística em si, mas esboçar uma tentativa de explicação de uma interconexão de temas que perpassam o mito da democracia, cujo desdobramento, no contexto brasileiro - que sustentou e ainda sustenta esse mito, para além do universo de ideias que subjazem a ele -, propaga-se para a esfera comportamental. Esse desdobramento, por sua vez, indica inúmeros e diversificados preconceitos, discriminação, violência e a centralidade de um grupo que não se reconhece dentro da forma como foi constituído o Brasil, em processos de miscigenação e hibridação sociocultural, dentre outros. Contudo, continua trabalhando com um centrismo pernicioso, que, na atualidade, se levanta na forma não apenas de discurso de ódio, mas de ações que atentam contra grupos já historicamente marginalizados.

Por isso, pretendemos fazer um estudo inicialmente bibliográfico para, posteriormente, produzirmos uma avaliação semântica de vestígios concernentes aos sentidos da palavra (in)tolerância, partindo de seu registro em dicionários gerais e etimológicos, uma vez que partimos da hipótese de que sua semântica inicial - indicada etimologicamente em sua raiz no latim - pode esclarecer alguns aspectos relacionados ao seu uso contemporâneo - conforme será demonstrado com manchetes e reportagens atuais - em que se liga a conflitos sociais bem demarcados e a comportamentos de violências física e simbólica sofridas pelos grupos vulneráveis e minoritários, apontando também para um discurso de ódio.

Para a organização das reflexões, num primeiro momento, discorremos sobre os conceitos de grupos minoritários (ou minorias) e grupos vulneráveis, procurando estabelecer diferenciações e também esclarecer alguns pontos de convergência. Posteriormente, fazemos uma explanação sobre minúcias subjacentes ao uso e 
importância dados à (in)tolerância de maneira geral, para depois dar um fulcro etimológico de base semântica por via diacrônica e adentrar no universo discursivo, no intuito de procurar ter acesso a uma relação importante de ser restaurada quanto às questões ideológicas envolvidas na dimensão da prática social a esse respeito. Partimos da ideia de que essa relação tem ganhado espaço ao se tornar elemento-chave para a compreensão de um discurso de ódio no contexto brasileiro, que, contrário aos princípios democráticos, em virtude do acesso cada vez maior à informação verificado na atualidade, ganha força como forma de ação de diferentes grupos em variadas esferas da sociedade, porém nem sempre respeitando os direitos fundamentais do ser humano.

\section{GRUPOS MINORITÁRIOS E GRUPOS VULNERÁVEIS}

A ideia de grupo minoritário e, por conseguinte, o conceito de minoria têm sido debatidos e compreendidos de maneiras diferentes por pesquisadores de várias áreas. Acselrad ${ }^{2}$ discute o conceito de minoria a partir de uma perspectiva iluminista, acreditando na ideia de que minoria não parece ser um termo adequado para representar os "grupos ideologicamente menos poderosos" por contrariar o ideal de união universal que o próprio Iluminismo defendia.

Carvalheiro ${ }^{3}$ demonstra, em sua pesquisa sobre a representação dos cabo-verdianos na mídia portuguesa, um conceito de minoria a partir da ideia do diferente e do numericamente menor, apontando para um suposto padrão como elemento gerador de invisibilidade e estereotipia.

Rifiotis ${ }^{4}$, por sua vez, parece compreender as minorias como grupos que poderiam, em circunstâncias específicas, correr o risco de perder a própria identidade por serem vitimizados por processos de controle e homogeneização.

Já Séguin5, a partir de uma perspectiva jurídica, relaciona as minorias aos chamados grupos vulneráveis, os quais são descritos por ela como grupos que sofrem discriminação e são vítimas de intolerância. Aqui, percebemos que grupos minoritários e grupos vulneráveis possuem elementos característicos em comum, embora não estabeleçam obrigatoriamente uma relação sempre de proximidade conceitual. O que parece comum está na estreita relação de afetamento no que tange ao poder que lhes é tirado, ao processo de dominação, à violência sofrida, à

2 ACSELRAD, Márcio. Por uma visão crítica de minoria. Crítica Cultural, v. I, n. I, jan./jun. 2006. Disponível em: 〈http://www3.unisul.br/paginas/ensino/pos/linguagem/critica/oIoI/o6.htm〉. Acesso em: Io jul. 20I4.

3 CARVALHEIRO, José Ricardo. Da representação mediática à recepção política. Discursos de uma minoria. Sociologia, problemas e práticas, n. 5I, p. 73-93, 2006. Disponível em: <http://www.scielo.oces.mctes.pt/pdf/spp/ n5I/n5Ia05.pdf >. Acesso em: 2 jul. 20I4.

4 RIFIOTIS, Theophilos. Nos campos da violência: diferença e positividade. 2006. Disponível em: <https:// www.academia.edu/305902I/Nos_campos_da_viol\%C3\%AAncia_diferen\%C3\%A7a_e_positividade $>$. Acesso em: 2 jul. 2014 .

5 SÉGUIN, Elida. Minorias e grupos vulneráveis: uma abordagem jurídica. Rio de Janeiro: Forense, 2002. 
marginalização social e a uma necessidade premente de tolerância que, segundo boa parte da literatura a esse respeito, não é verificada.

Para problematizar as concepções de minorias e de grupos vulneráveis, podemos começar especialmente por Séguin ${ }^{6}$, para quem "as primeiras seriam caracterizadas por ocupar uma posição de não dominância no país onde vivem” e os segundos por se "constitu[í]r[em] num grande contingente numericamente falando [...]". Embora com nomenclatura diferenciada, a autora esclarece que tanto os grupos vulneráveis quanto as minorias sofrem discriminação e são vítimas da intolerância, razões que a levam a não se preocupar em trabalhar essas categorias de forma muito distinta.

Segundo Rogers e Ballantyne7, existem fontes de vulnerabilidade, a partir das quais seria possível estabelecer uma tipificação básica:

a) vulnerabilidade extrínseca - ocasionada por circunstâncias externas, como falta de poder socioeconômico, pobreza, falta de escolaridade ou carência de recursos; e b) vulnerabilidade intrínseca - causada por características que têm a ver com os próprios indivíduos, tais como doença mental, deficiência intelectual, doença grave, ou os extremos de idade (crianças e idosos) ${ }^{8}$.

Um ponto de vista que mostra a convergência entre grupos minoritários e grupos vulneráveis é trazido por Sodré9. Todo seu interesse recai sobre a conceituação de minoria ao explicar que apenas o sentido inicial de minoria tem como ponto de partida a ideia de inferioridade quantitativa, exatamente por evocar o contrário de maioria. Para ele, a grande importância dessa categoria reside no fato de estar atrelada à clássica democracia representativa. Conforme Sodré ${ }^{10}$ explicita, na democracia deve predominar a vontade da maioria, como argumento quantitativo, mas, do ponto de vista qualitativo, democracia é um regime de minorias, porque só no processo democrático a minoria pode se fazer ouvir. Por isso, o autor caminha para sustentar que minoria, em seu entender, é uma voz qualitativa, cujo princípio de moção é o impulso de transformação. Essa é a razão para a proposição de minoria como um lugar, não como espaço abstrato, mas como localização do corpo, indicando um lugar ocupado, onde ocorre o afetamento do território pela presença humana. $\mathrm{Ou}$ seja, é um lugar acima de tudo de ação humana. Assim, destaca que "[m]inoria não é, portanto, uma fusão gregária mobilizadora, como a massa ou a multidão ou ainda um grupo, mas principalmente um dispositivo simbólico com uma intencionalidade ético-política dentro da luta contra-hegemônica"זr.

\footnotetext{
6 Ibidem.

7 ROGERS, Wendy; BALLANTYNE, Angela. Populações especiais: vulnerabilidade e proteção. RECIIS - R. Eletr. de Com. Inf. Inov. Saúde, Rio de Janeiro, v. 2, p. 3I-4I, dez. 2008.

8 Ibidem, p. 32, itálico dos autores.

9 SODRÉ, Muniz. Por um conceito de minoria. In: PAIVA, Raquel; BARBALHO, Alexandre (Org.). Comunicação e cultura das minorias. São Paulo: Paulus, 2005. p. II-I4.

Io Ibidem.

II Ibidem, p. II.
} 
O ponto de convergência aparece no momento em que o autor traça as características básicas de uma minoria, quais sejam:

I) vulnerabilidade jurídico-social - por ser um grupo institucionalizado pelas regras do ordenamento jurídico-social vigente, logo, muitas vezes não acampado pelas políticas públicas, a razão para lutar por voz e reconhecimento societário de seu discurso;

2) identidade in statu nascendi - porque se apresenta sempre in statu nascendi, compreendido como uma entidade em formação que se alimenta da força e do ânimo dos estados nascentes ou de um eterno recomeço;

3) luta contra-hegemônica - parte sempre de uma constante luta pela redução do poder hegemônico, mas, normalmente, sem objetivo de tomada do poder pelas armas; 4) estratégias discursivas - uso de estratégias de discurso e de ações demonstrativas (passeatas, por exemplo) como os principais recursos de luta na atualidade.

Sodré ${ }^{\mathrm{I2}}$ finaliza afirmando que "minoria é uma recusa de consentimento, é uma voz de dissenso em busca de uma abertura contra-hegemônica no círculo fechado das determinações societárias. É no capítulo da reinvenção das formas democráticas que se deve inscrever o conceito de minoria".

Adorno $^{\mathrm{I} 3}$, por exemplo, explica que grupos considerados dominantes se "utilizam da violência como se fosse meio natural de solução de conflitos, seja nas relações entre classes sociais, seja nas relações intersubjetivas”. Nesse sentido, a violência torna-se um dos maiores fatores geradores da vulnerabilidade, o que pode não ter a ver especificamente com a ideia de quantidade indicada pela palavra "minoria".

É relevante buscarmos também subsídios em Zaluar ${ }^{\mathrm{I} 4}$, cujos trabalhos relacionam essa temática à formação de gangues, galeras e quadrilhas e a um problema educacional.

Como podemos perceber, todos os autores indicam que minorias e grupos vulneráveis originam-se em relações de assimetria social (econômica, educacional, cultural etc.). Nessa perspectiva, minoria pode ser definida a partir de uma particularização de um grupo, já que a maioria se define por um agrupamento generalizado, ou seja, por um processo de generalização baseado na indeterminação de traços, os quais indicam um padrão de suposta normalidade, considerada majoritária em relação ao outro que destoar dele. A vulnerabilidade advém, pois, de pressões desse suposto padrão de normalidade, que pressiona tudo e todos que possam ser considerados diferentes. A violência, por sua vez, tanto pode ser física quanto

I2 Ibidem, p.I4.

I3 ADORNO, Sérgio. A violência na sociedade brasileira: um painel inconcluso em uma democracia não consolidada. Sociedade e Estado, São Paulo, v. Io, n. 2, p. 299-342, jul./dez. I995. p. 32I.

I4 ZALUAR, Alba Maria. Gangues, galeras e quadrilhas: globalização, juventude e violência. In: VIANNA, Hermano (Org.). Galeras cariocas: territórios de conflitos e encontros culturais. Rio de Janeiro: Ed. da UFRJ, I997. p. I7-57; ZALUAR, Alba Maria. Desafios para o ensino básico na visão dos vulneráveis. Sociologias, Porto Alegre, v. I, p. 228-249, I999; ZALUAR, Alba Maria. Exclusion and public policies: theoretical dilemmas and political alternatives. Revista Brasileira de Ciências Sociais, v. I, p. 25-42, 2000; ZALUAR, Alba Maria. Violence in Rio de Janeiro: styles of leisure, drug use, and trafficking. International Social Science Journal, Londres and Paris, Unesco, v. LIII, n. 3, p. 369-379, 200 I. 
simbólica, originária dessa pressão, que, muitas vezes, na forma de preconceito e rejeição, marginaliza e discrimina o diferente.

\section{A PROBLEMÁtica da (IN)TOLERÂNCIA: UM OLHAR LINGUÍSTICO-DISCURSIVO POR VIAS ETIMOLÓGICAS}

Como podemos notar, há diferentes vieses relacionados aos conceitos de grupos minoritários (ou minorias) e grupos vulneráveis, além de sua relação com outros temas já citados, como o da violência. Por isso, verificamos uma relação bastante específica com a problemática da (in)tolerância, o que tem sido pouco trabalhado no domínio dos estudos linguísticos.

As questões ligadas à (in)tolerância são, portanto, de extrema importância exatamente porque trazem à tona o problema da violência, do preconceito e da discriminação, que acontece por uma suposta "normalidade" e "superioridade" entre grupos no interior da sociedade. Essas questões são antigas e remontam, especialmente, ao pensamento filosófico acerca da intolerância religiosa. Embora não seja esse o foco deste artigo, a fim de retomarmos essas discussões, vamos adentrar nesse nicho para, a partir dessa especificidade, caminharmos para o universo linguístico-discursivo que envolve a palavra tolerância e, por conseguinte, as demais palavras de mesma raiz que a reverberam.

Conforme Bobbio, Matteucci e Pasquino ${ }^{\mathrm{I5}}$, os primeiros registros de estudos e da preocupação com o tema (in)tolerância datam do século XVI, embora tenha sido no século XVIII que se deu o desenvolvimento moderno do chamado princípio de tolerância.

Para iniciarmos nossas reflexões, é preciso lembrar que, historicamente, duas instituições preconizaram e desencadearam grandes movimentos no interior das sociedades, quais sejam, o Estado e a Igreja, os quais, muitas vezes, se unificavam em função de determinados objetivos. Em grande medida, isso propiciava o exercício do poder, sendo o Estado responsável pela instrumentalização desse poder, diversas vezes gerando violência, e a religião contribuindo com seu trabalho evangelizador e catalisador ideológico de justificativas tanto de suas práticas quanto das ações do Estado.

O filósofo empirista John Locke (I632-I704) foi um dos grandes pensadores acerca do que envolvia a problemática da tolerância, o que se encontra na Carta acerca da tolerância ${ }^{\mathrm{I} 6}$, na qual, de maneira veemente, advogava um estado laico como forma de garantia de uma sociedade que respeitasse as diferenças.

Sua base era desenvolvida em cima da própria noção de diferença, já que, para ele, se houvesse apenas uma religião verdadeira, entendida como caminho para o céu, certamente se produziria um grande conflito interno no indivíduo, pois, com isso, deveria abdicar da razão que o tornava mortal para procurar a divinização.

I5 BOBBIO, Norberto; MATTEUCCI, Nicola; PASQUINO, Gianfranco. Dicionário de política. Brasília: Ed. da UnB, I998.

I6 LOCKE, John. Carta acerca da tolerância. São Paulo: Abril Cultural, I978. 
Isso significaria a aceitação tácita e cega das doutrinas impostas por seu príncipe e o culto a Deus na maneira formulada pelas leis de seu país a despeito de sua razão e consciência ${ }^{\mathrm{I7}}$.

Sendo assim, para o filósofo, a tolerância e a relação entre os estados laicos e as religiões estão assentadas no respeito à individualidade e à diversidade de opinião, mas também na liberdade de expressão.

Outro filósofo que se voltou para o tema foi François Marie Arouet (Voltaire, I694-I778). Como filósofo iluminista, tinha como pedra fundamental a razão, o que, muitas vezes, ia frontalmente contra a Igreja e determinados ditames autoritários. Devido a essa forma de pensamento, várias das formas de interpretação dos fenômenos produzidas pela Igreja foram consideradas superstições. Nesse momento é que Voltaire escreveu seu Tratado sobre a tolerância ${ }^{\text {I8 }}$. Com um modo bastante peculiar de compreender a intolerância, o filósofo também se preocupou com a intolerância religiosa como uma forma de obtenção de poder com início em uma religião dominante via imposição. Entretanto, esse filósofo sustentou a tese de que não existiam verdades absolutas, pois as verdades eram relativas, pensamento a partir do qual se deveria garantir a paz e a tolerância entre todos, o que se traduziria em respeito para com as diversas crenças e religiões.

Voltaire $^{\text {I9 }}$ afirmava que não dependia do homem acreditar ou não em algo, mas que dele dependia o fato de respeitar os costumes dos outros. "Se dissesses que é crime não acreditar na religião dominante, tu mesmo acusarias os primeiros cristãos, teus antepassados, e justificarias aqueles que acusas de tê-los entregue aos suplícios”2o. Por isso, quanto mais uma religião fosse divina, menos estaria a cargo do indivíduo comandá-la, uma vez que, para ele, a intolerância só tinha a capacidade de produzir hipócritas e rebeldes.

Montesquieu ${ }^{2 I}$, por sua vez, também voltado para as religiões, compreende que, se um Estado crê que pode abarcar dentro de si várias religiões, também precisa garantir que estas se tolerem entre si para que não seja gerada nem opressão, nem repressão sobre elas.

Com um cunho mais geral, o trabalho de Stouffer ${ }^{22}$ é considerado o primeiro grande estudo sobre tolerância social. Entretanto, não apresenta uma definição clara desse termo, relacionando-o à atribuição de direitos a pessoas com pontos de vista discordantes, o que é registrado em vários dicionários, como poderemos ver adiante. Nesse sentido, o estudo estava ligado a grupos específicos, entre os quais se podem

I7 Ibidem, p. 6.

I8 VOLTAIRE, François Marie Arouet. Tratado sobre a tolerância. São Paulo: Escala, 2000.

I9 Ibidem.

20 Ibidem, p. 280.

2I MONTESQUIEU,Charles-Louis de Secondat. O espírito das leis. Curitiba: Juruá, 2005. p. I5I.

22 STOUFFER, Samuel Andrew. Communism, conformity and civil liberties: a cross section of the nation speaks its mind. New York: Doubleday, 1955. 
destacar judeus, ateus e socialistas. Por essa razão, Sullivan, Piereson e Marcus ${ }^{23}$ criticaram o estudo de Stouffer ${ }^{24}$ e incluíram questões que permitiam aferir se os inquiridos - os grupos estudados - eram adversos aos grupos-alvo em estudo, defendendo que só nesse caso se poderia considerar a existência de tolerância. Trabalhando com a intolerância social de maneira geral, esses estudos foram o ponto de partida para muitas revisões e para que a questão fosse cada vez mais debatida.

No intuito de contribuir com essas discussões, escolhemos o viés etimológico a partir do qual discorreremos a respeito das possíveis razões pelas quais, do universo das ideias, esse tema tem se relacionado ao discurso de ódio e se manifestado na forma de ação social na esfera comportamental. Para iniciarmos a discussão, partimos do verbete tolerância em um dos dicionários mais consumidos e respeitados no Brasil, o Aurélio.

tolerância. [Do lat. Tolerantia.] S. f. I. Qualidade de tolerante. 2. Ato ou efeito de tolerar. 3. Pequenas diferenças, para mais ou para menos, permitidas por lei no peso ou no título das moedas. 4. Tendência a admitir modos de pensar, de agir e de sentir que diferem dos de um indivíduo ou de grupos determinados, políticos ou religiosos. 5 . Diferença máxima admitida entre um valor especificado e o obtido; margem especificada como admissível para o erro em uma medida ou para discrepância em relação a um padrão. 6. Imun. Incapacidade, por parte de um indivíduo, de desencadear, em face da exposição a um antígeno, a resposta imunológica que esse antígeno provoca em outros indivíduos; imunoparalisia. 7. Med. Capacidade de tolerar, sem efeito danoso para o organismo, doses de medicamento mais altas do que as habitualmente suportáveis. 8. Med. Diminuição de efeito de uma droga usada em caráter permanente e em doses inalteradas ${ }^{25}$.

A partir desse verbete, percebemos que, para a discussão do tema, no que se refere aos conflitos na esfera social, apenas as acepções I, 2 e 4 são produtivas. As acepções I e 2 são tautológicas; logo, pouco elucidativas. A acepção 4 parte da ideia de admissão de modos de pensar, agir e sentir de indivíduos ou grupos em duas esferas específicas, isto é, a política e a religiosa, embora os problemas já tenham se disseminado para muitas outras esferas, como a do esporte, com os vários casos de racismo no

23 SULLIVAN, John; PIERESON, James; MARCUS, George. Political tolerance and American democracy. Chicago: University of Chicago Press, I982.

24 STOUFFER, Samuel Andrew, op. cit.

25 FERREIRA, Aurélio Buarque de Holanda. Novo dicionário Aurélio da língua portuguesa. Curitiba: Positivo, 2009 p. I960. 
futebol ${ }^{26}$, os problemas dos povos indígenas ${ }^{27}$, das mulheres ${ }^{28}$ e dos homossexuais ${ }^{29} \mathrm{e}$ os constantes conflitos relacionados às religiões de matriz africana ${ }^{30}$.

As acepções anteriormente analisadas se repetem - com exceção da ordem progressiva de organização lexicográfica dos verbetes, a qual poucas vezes coincidia - da mesma forma em Michaelis ${ }^{31}$, Caldas Aulete ${ }^{32}$, Houaiss ${ }^{33}$ e no Dicionário brasileiro da língua portuguesa ${ }^{34}$. O Dicionário da língua portuguêsa - dicionário do povo ${ }^{35}$ registra apenas uma acepção que mistura os elementos das acepções I, 2 e 4 do Aurélio.

Embora, em termos de números progressivos indicativos das acepções, o registro destas nem sempre coincida numa ordem em comum, a percepção se mantém e o conteúdo também, pois os dicionários apenas se diferenciam na quantidade de informação que é dada. O que se repete nos dicionários de maneira geral são as acepções ligadas a medicamentos, uso exemplificado com as orações "O doente não tolerou o medicamento" ${ }^{36} \mathrm{e}$ "O paciente tolerou bem o medicamento" ${ }^{37}$, e religião, essa última sem exemplos. Ou ainda incluem as relações sociais interpessoais em nível micro devido ao uso de tolerar-se, indicando reciprocidade como em "Davam-se bem outrora; hoje não se toleram" ${ }^{38}$ e "Amigos desde a infância, hoje não se toleram" ${ }^{39}$. Nesse último caso, são abarcadas outras formas de produção desse sentido de reciprocidade como em "A felicidade conjugal baseia-se na mútua tolerância dos cônjuges" ${ }^{\prime \prime}$.

Diferentemente dos outros dicionários gerais usuais no cotidiano das pessoas

26 Cf. CERVI, Thales de Almeida Nogueira. Intolerância e racismo no futebol: a racialização do outro. ComCiência, Campinas: Unicamp, v. I59, p. IO-I6, 20I4.

27 Cf. LOPES, Aline Luciane; CORREAA, Darcísio. O multiculturalismo e os direitos fundamentais dos povos indígenas: a luta pela igualdade no Brasil da intolerância. Rev. Ciên. Jur. e Soc. da Unipar, Umuarama, v. II, n. 2, p. 47I-489, jul./dez. 2008.

28 Cf. MONTE, Izadora Xavier do. A violência contra a mulher no discurso diplomático brasileiro. Boletim Meridiano 47, Brasília: UnB, v. I2, p. 36-4I, $20 I I$.

29 Cf. ALMEIDA, Marco Bettine; SOARES, Alessandro da Silva. O futebol no banco dos réus: o caso da homofobia. Revista SÍNTESE Direito Desportivo, v. 3, p. 68-82, 20I4.

30 Cf. SILVA, Vagner Gonçalves da (Org.). Intolerância religiosa: impactos do neopentecostalismo no campo religioso afro-brasileiro. São Paulo: Edusp, 2007.

3I MICHAELIS: moderno dicionário da língua portuguesa. São Paulo: Melhoramentos, I998.

32 CALDAS AULETE. Lisboa, Portugal: E. Pinto Barto; Rio de Janeiro, Brasil: Delta, I980.

33 HOUAISS da língua portuguesa. Rio de Janeiro: Objetiva, 2007.

34 DICIONÁRIO brasileiro da língua portuguesa. São Paulo: Mirador Internacional, I975.

35 DICIONÁRIO da língua portuguêsa - dicionário do povo. 34. ed. Rio de Janeiro: F. Alves, I9--.

36 MICHAELIS, op. cit., p. 2.077.

37 HOUAISS, op. cit., p. 2.730.

38 MICHAELIS, op. cit., p. 2.077.

39 HOUAISS, op. cit., p. 2.710.

40 CALDAS AULETE, op. cit. p. 3.590. 
contrastados nesta análise, os dicionários Caldas Aulete ${ }^{4 \mathrm{I}}$ e Houaiss ${ }^{42}$ trazem explicitações etimológicas, enquanto o Michaelis ${ }^{43}$ apenas se limita a registrar sua raiz no latim em tolerare, o que também verificamos em Nascentes 44 , apesar de este ser etimológico e esperarmos explicitações a respeito da palavra em seu étimo.

Seja como for, pelo que foi constatado na pesquisa do termo, inclusive pela repetição do conteúdo das acepções, acreditamos que os problemas inter-relacionados a essa palavra no contexto brasileiro não estejam de verdade contemplados em sua complexidade, ou, pelo menos, estejam apenas aventados, indicados nos matizes que remontam a etimologia do termo, num viés mais geral, porque os dicionários consultados não tocam, semanticamente, no cerne de sua existência e multiplicidade de matizes.

O que nos ampara em termos de possibilidade de análise dos verbetes ancora-se no pensamento de Biderman ${ }^{45}$, a partir do qual o léxico constitui uma forma de registrar o conhecimento do universo devido ao processo de nomeação da realidade em que o homem rotula as entidades, apropriando-se desse real. Isso significa, nas palavras da autora ${ }^{46}$, que "a geração do léxico se processou e se processa através de atos sucessivos de cognição da realidade e de categorização da experiência, cristalizada em signos linguísticos: as palavras". Por essa razão, podemos perceber que o léxico pode carregar e carrega em sua significação aspectos importantes da visão de mundo que os indivíduos possuem. Para a autora, as palavras que são geradas pelo sistema de categorias léxico-gramaticais de uma língua são rótulos por meio dos quais o ser humano interage cognitivamente com o seu meio.

Tomemos como ponto de partida o registro de tolerância e tolerar no Dicionário do latim essencial 47 :

tolĕro,-as,-are,-aui,-atum. (mesma raiz de tollo). Suportar, tolerar, sofrer. Sustentar, aguentar. Persistir, manter. Alimentar. Resistir, combater.tolerantǐa,-ae, (f.). (tolěro). Tolerância, paciência. Capacidade de suportar com firmeza, com constância.

Tendo em mente o que vimos refletindo e os verbetes acima, tomemos agora, etimologicamente, o verbo tolerar:

\footnotetext{
4I Ibidem.

42 HOUAISS, op. cit., p. 2.730.

43 MICHAELIS, op. cit., p. 2.077.

44 NASCENTES, Antenor. Dicionário etimológico da língua portuguêsa. Rio de Janeiro: F. Alves, I932.

45 BIDERMAN, M. T. C. As ciências do léxico. In: OLIVEIRA, A. M. P. P.; ISQUERDO, A. N. As ciências do léxico: lexicologia, lexicografia, terminologia. Campo Grande: UFMS, $200 \mathrm{I} \mathrm{p.} \mathrm{I3.}$

46 Ibidem.

47 REZENDE, Antônio Martinez da; BIANCHET, Sandra Braga. Dicionário do latim essencial. Belo Horizonte: Crisálida/Autêntica, 2005.
} 
Tolerar vb. 'suportar, consentir' XVI. Do lat. tolerare // INtolerÂNCIA XVI. Do lat. intolerantia //INtolerANTE I8I3. Do lat. in-tolerans-antis // INtolerÁVEL I8I3. Do lat. intolerabilis $-e / /$ tolerABIL.IDADE XX // tolerADO I8I3. Do lat. toleratus, part. pass. De tolerare // tolerÂNCIA I8I3. Do lat. tolerantia // tolerANTE I8I3. Do lat. tolerans -antis // tolerÁVEL. I8I3. Do lat. tolerabilis $-e^{48}$.

Logo de início, acreditamos que os problemas subjacentes à (in)tolerância estejam apontados de maneira bem mais clara na acepção ligada a "suportar" na medida em que pressupõe o conflito e o sentimento negativo em seu interior. Isso significa uma possível sinonímia entre estruturas como "Eu não te suporto" e "Eu não te tolero" e similares no uso comum, a exemplo de “Não tolero corrupção', diz Dilma a jornal francês"49, "A elite que Lula não suporta” 50 , "Eu não tolero abusos" ${ }^{51}$ e "Eu não suporto ficar descrevendo as coisas" ${ }^{2}$.

Essa similaridade semântica admite e coloca em cena o problema da intolerância a partir do instante em que se assume um sentimento negativo que não se configura como algo situacional e transitório, mas de caráter permanente, o qual é nutrido com relação a outrem por razões sociais perpetuadas historicamente, por diversos motivos. Dessa maneira, percebemos uma construção intersubjetiva tensiva e conflituosa de um eu que só se configura como tal na alteridade, isto é, em sua relação com o outro, num contexto em que muitas variáveis estão envolvidas. E, nessa mesma esteira, diferenças no modo de agir, pensar e sentir também são suportadas, ou seja, toleradas, porque nunca foram verdadeiramente colocadas como alternativas legítimas numa sociedade plural e que se quer democrática.

Diante do exposto, é particularmente interessante a acepção 5 do dicionário Michaelis ${ }^{53}$, que consta também no Dicionário brasileiro da língua portuguesa ${ }^{54}$, pois, com isso, ambas as fontes parecem ser incisivas para corroborar nossa hipótese de que as raízes latinas mantêm-se semanticamente como uma forma de explicação da inconsistência do uso do termo tolerância no contexto brasileiro, por este apenas escamotear os conflitos entre os grupos, que, antes de se respeitarem, mantêm-se em

48 CUNHA, Antônio Geraldo da. Dicionário etimológico Nova Fronteira da língua portuguesa. Rio de Janeiro: Nova Fronteira, I982, p. 774 .

49 VEJA. "Não tolero corrupção”, diz Dilma a jornal francês. Disponível em: <http://veja.abril.com.br/noticia/ brasil/dilma-diz-que-nao-tolera-corrupcao-e-elogia-lula>. I3/I2/20I2. Acesso em: I6 mar. 2016.

50 AZEVEDO, Reinaldo. A elite que Lula não suporta. Blog Reinaldo Azevedo. Veja Colunistas. Disponível em: 〈http://veja.abril.com.br/blog/reinaldo/geral/a-elite-que-lula-nao-suporta〉. 2I/9/20Io. Acesso em I6 mar. 2016. 5 I AMÂNCIO, Thiago. Entidades criticam governo Alckmin por omitir dados de violência policial. Folha de S.Paulo, Cotidiano, 23/Io/20I5. Disponível em: <http://wwwI.folha.uol.com.br/cotidiano/20I5/Io/I69758I-entidadescriticam-governo-alckmin-por-omitir-dados-de-violencia-policial.shtml〉. Acesso em: I6 mar. 2016.

52 ALMEIDA, Marco Rodrigo. Edyr Augusto retrata mundo alucinado em um dos melhores livros do ano. Folha de S. Paulo, Ilustrada, 22/8/20I5. Disponível em: <http://wwwI.folha.uol.com.br/ilustrada/20I5/o8/I67I9I5-edyr-augusto-retrata-mundo-alucinado-em-um-dos-melhores-livros-do-ano.shtml>. Acesso em: I6 mar. 2016.

53 MICHAELIS, op. cit., p. 2.077.

54 DICIONÁRIO brasileiro da língua portuguesa, op. cit., p. 672. 
tensão, excluindo o outro, apenas suportando o outro, demonstrando a semântica negativa etimologicamente marcada: “5. Disfarce ou dissimulação a respeito de uma coisa proibida" 55 .

Numa pretensa democracia, o poder deveria ser diluído em favor do respeito social e da igualdade de direitos na garantia da dignidade da pessoa humana como algo natural. Entretanto, o preconceito (ver, por exemplo, a reportagem "Poder feminino ganha reforço na luta contra o preconceito"56) e os episódios de ódio (ver, por exemplo, a reportagem "Podem as mulheres falar?"57) são proibidos e coibidos por lei. Logo, aqueles que não suportam a diferença precisam disfarçar ou dissimular seus sentimentos negativos em relação a outrem para não sofrerem as sanções da lei. Ou seja, eles apenas toleram o diferente, não os respeitam como iguais, demonstrando a pseudodemocracia no contexto brasileiro.

Por isso, é importante destacar que Fontinha, no seu Novo dicionário etimológico da língua portuguesa ${ }^{58}$, também registra essa acepção:

Tolerância, s. f. (Lat. Tolerantia $(m))$ - Qualidade de tolerante; indulgência; condescendência; aç̧ão ou resultado da ação de tolerar sem o consentimento expresso da lei; dissimulação ou disfarce acerca duma coisa proibida; direito que se reconhece aos outros de terem opiniões políticas ou religiosas diferente ou, até, diametralmente opostas às nossas; perdão dos erros ou abusos dos outros ${ }^{59}$.

E essas ideias são repetidas no verbete "tolerar" do mesmo dicionário:

Tolerar, v. tr. (Lat. Tolerare) - Suportar, sofrer; levar com paciência; condescender com; dissimular certas coisas, sem no entanto as consentir expressamente, logo que elas não sejam lícitas; permitir (o livre exercício dos cultos ou das crenças de alguém); desculpar; perdoar; dar tácito consentimento $a^{60}$

O Dicionário da língua portuguêsa - dicionário do povo ainda acrescenta que tolerância é "permissão, consentimento tácito do que merece censura, castigo ou correção" "I o que é reverberado no Caldas Aulete ${ }^{62}$ no início do verbete quando afirma sua definição do termo como "consentir, permitir tacitamente (o que é

55 MICHAELIS, op. cit., p. 2.077; DICIONÁRIO brasileiro da língua portuguesa, op. cit., p. I.7I2.

56 Disponível em: <http://oglobo.globo.com/sociedade/poder-feminino-ganha-reforco-na-luta-contra-preconceito-I-I8826384>. 8/3/20I6. Acesso em: I6 mar. 2016.

57 LIMA, Daniela. Podem as mulheres falar?. Folha de S. Paulo, Ilustríssima, 6/I2/20I5. Disponível em: <http:// wwwI.folha.uol.com.br/ilustrissima/20I5/I2/I7I4573-contra-a-violencia-naturalizada-sejamos-todos-barbaros. shtml>. Acesso em: I6 mar. 2016.

58 FONTINHA, Rodrigo. Novo dicionário etimológico da língua portuguesa. Porto: Domingos Barreira, s.d.

59 Ibidem, p. I757.

60 Ibidem, p. I758.

6I DICIONÁRIO da língua portuguêsa - dicionário do povo, op. cit., p. 672.

62 CALDAS AULETE, op. cit. 
censurável ou merece castigo): O governo de Afonso V pela sua indulgência em tolerar aos grandes vassalos os maiores abusos (R. da Silva)"63; ou seja, o que é tolerado, suportado, é sempre passivo em relação a outro polo que é ativo no processo de avaliação. É interessante destacar que esse registro do que precisa ser dissimulado porque merece censura está registrado em Pinto ${ }^{64}$, no Dicionário da língua brasileira, datado de I832, e é nesse mesmo sentido que aparecem como interligadas, no Dicionário de palavras interligadas, analógico e de ideias afins ${ }^{65}$, palavras como aceitabilidade, aceitação, acolhida, acolhimento, acolho, admissão, assentimento e submissão.

Embora Bobbio, Matteucci e Pasquino ${ }^{66}$ tratem de forma específica da tolerância religiosa, percebemos que é possível expandir o que é explicado no seguinte trecho: “[a] Tolerância para com os dissidentes é, portanto, aceita como um mal necessário quando não é possível reprimir o dissenso, ou seja, um mal menor quando o custo da repressão resultaria excessivo”. O diferente é, então, visto como dissidência, como um mal que deve ser reprimido, mas ressalvados os excessos.

A isso, então, se conecta o fato de que tudo o que é tolerado tem pressuposição de merecimento de censura, castigo ou correção, uma vez que, conforme o verbete acima, deve ser perdoado, desculpado, admitido, permitido e/ou consentido ${ }^{6}$. Isso significa uma negatividade subjacente ao termo, já apontada etimologicamente, fortalecendo-se no contexto brasileiro contemporâneo.

Machado, por sua vez, registra o verbete tolerar de uma forma que também coaduna com nossa interpretação do contexto brasileiro, confirmando nossa hipótese:

Tolerar, $v$. Do lat. Tolerare, <<levar, suportar um peso, um fardo; agüentar, suportar, sofrer; agüentar-se; ficar, persistir; suster, manter, sustentar; resistir a, combater 〉; por via culta. No séc. XVI: <<...a deleitação dos mais sentidos era tanta que fazia não só tolerar o fervor do sol, mas quase não no sentir » Frei Luís de Souza, Vida de D. Frei Bartolomeu dos Mártires, VI, cap. I3, vol. III, p. 26I, Ed. De I946 68.

Assim, todas as palavras de mesma raiz trazem essa pressuposição em sua semântica e em todas as suas formas, flexões e derivações (nominais, adjetivais, adverbiais etc.). Por isso, não é apenas o derivado intolerância que se mostra problemático, mas a própria ideia de tolerância, em cuja raiz se reforça uma falsa condição pacífica e apaziguadora de conflitos, que é âncora para os demais

63 Ibidem, p. 3.590.

64 PINTO, L. M. S. Dicionário da língua brasileira. Ouro Preto: Typografia de Silva, I832.

65 PESSEK, Kurt. Dicionário de palavras interligadas, analógico e de ideias afins. Brasília: Thesaurus, 2010.

66 BOBBIO, Norberto; MATTEUCCI, Nicola; PASQUINO, Gianfranco, op. cit., p. I246.

67 Ver, também, DICIONÁRIO brasileiro da língua portuguesa, op. cit.; DICIONÁRIO da língua portuguêsa - dicionário do povo, op. cit.; FONTINHA, Rodrigo, op. cit.; MICHAELIS, op. cit.; HOUAISS, op. cit.; e CALDAS AULETE, op. cit.

68 MACHADO, José Pedro. Dicionário etimológico da língua portuguesa: com a mais antiga documentação escrita e conhecida de muitos dos vocábulos estudados. Lisboa: Confluência, I952-I959. p. 209 I. 
problemas a ela relacionados, como o preconceito, a discriminação e as violências física e simbólica, dentre outros, todos originários em ideologias grupais, na pretensa superioridade e centralidade de alguns em detrimento da diversidade e da diferença que constitui a sociedade que pressupostamente deveria ser uma democracia.

Esse parece ser o motivo, por exemplo, de as acepções fornecidas pelos diversos dicionários consultados - tanto os de caráter geral quanto os especificamente etimológicos - se relacionarem apenas a verbos que pressupõem uma passividade verificável somente para grupos minoritários e vulneráveis na sua relação com outros grupos e agentes humanos, quando procura conceituar "suportar" com "sofrer", "tolerar", "aturar" e "admitir". Nesses casos, os grupos minoritários e vulneráveis são colocados na condição de serem avaliados ou aceitos - como aparece o verbo "aceitar" em Houaiss ${ }^{69}$-, tanto que o exemplo utilizado pelo autor é "Anos a fio suportou calúnias dos opositores", o que de certa maneira já pode ser percebido etimologicamente, quando da análise do latim suportare, como "aquilo que suporta alguma coisa"70, ou seja, que precisa aguentar, carregar algo; por extensão, admitir aquilo que verdadeiramente não quer. Por isso, Houaiss ${ }^{7 \mathrm{I}}$ adverte que, etimologicamente, "tolerar" significa "suportar (raro no sentido físico de suportar um peso, um fardo", mas de "sofrer, aturar"72, ou seja, raro, mas possível, o que pode explicar a forma como a diferença é vista contemporaneamente, isto é, metaforicamente como um fardo, um peso social a ser suportado, tolerado, aturado, aguentado.

Em outras palavras, quando analisamos o contexto em que "tolerar" é usado, um grupo considerado central "tolera", ou seja, assume o polo ativo, enquanto o que resta aos grupos marginalizados é a passividade de "ser tolerado", "suportado", "aguentado" como se numa sociedade democrática não merecessem ou já não possuíssem voz e vez, bem como se não colaborassem ativamente para tudo o que nela existe. Foram encontrados os seguintes exemplos nos dicionários pesquisados, demonstrando o aspecto negativo de tolerar: "Tolerava pacientemente o mau gênio da esposa" "Tolerava aquelas ações repulsivas"74 e "O pai tolerava os excessos do filho"75.

Nesse sentido é que observamos a possibilidade de extensão semântica tanto em termos de medida quanto em termos de análise humana à acepção 5 do verbete "tolerância" em Ferreira ${ }^{76}$ (que se repete igualmente ou de forma parecida em Houaiss $^{77}$ e Michaelis ${ }^{78}$ : "Diferença máxima admitida entre um valor especificado e

69 HOUAISS, op. cit, p. 2.730.

70 CUNHA, Antônio Geraldo da, op. cit., p. 745.

7I HOUAISS, op. cit.

72 Ibidem, p. 2.730. Ver também MACHADO, José Pedro, op. cit., p. 2.09I.

73 MICHAELIS, op. cit., p. 2.077.

74 Ibidem; DICIONÁRIO brasileiro da língua portuguesa, op. cit., p. I.7I2.

75 HOUAISS, op. cit., p. 2.730.

76 FERREIRA, Aurélio Buarque de Holanda, op. cit., p. I.960.

77 HOUAISS, op. cit.

78 MICHAELIS, op. cit. 
o obtido; margem especificada como admissível para o erro em uma medida ou para discrepância em relação a um padrão”. Partimos, portanto, na esfera social, da ideia de diferença, numa espécie de gradação, com um valor admissível no que tange a um erro ou a alguma discrepância de um padrão. Por isso, certos grupos sofrem em maior ou menor grau os problemas ligados à chamada intolerância.

Tais problemas, claramente, demonstram a grande fragilidade brasileira no que tange a seu ideal de democracia quando vemos tantos episódios de violência física (ver reportagem "Jovem diz ter sido agredido após discutir com aluna ao pedir silêncio em sala”79) e simbólica (a exemplo da reportagem "Terceirizado, I9o tem atraso de salários e denúncias de assédio”" ), de discriminação (ver, por exemplo, a reportagem “4 em cada Io estudantes já sofreram violência na escola”"), de racismo (ver "É bom saber que uma denúncia vai adiante neste país', diz Taís Araújo sobre prisão de responsáveis por ofensas racistas" ${ }^{2}$ ) e de sexismo (ver "Livros escolares perpetuam sexismo', diz Unesco”»3), dentre outras doenças socioculturalmente transmissíveis. Essas doenças se dão, em primeiro lugar, na esfera ideológica no interior das práticas sociais cotidianas antes de ganharem um discurso exclusivista e excludente, que tem se tornado ponto de partida para um discurso de ódio, que se dissemina rapidamente. O que chama atenção é que atualmente esse discurso tem ganhado cada vez mais espaço no domínio comportamental, gerando inúmeros problemas e crimes que têm por base a intolerância (ver, por exemplo, os casos de ataque aos terreiros, como na reportagem "Religiões de raiz africana pedem investigação de grupo Gladiadores do Altar"84). Sendo assim, a intolerância pode ser vista como um conjunto de ideias, ideologias e atitudes (por exemplo, o desrespeito) contrário a qualquer princípio democrático que deveria pulverizar o poder em uma via de mão dupla ao cobrar os

79 BIANCHI, Camila. Jovem diz ter sido agredido após discutir com aluna ao pedir silêncio em sala. Folha de S.Paulo, Cotidiano, 22/3/20I5. Disponível em: <http://wwwI.folha.uol.com.br/cotidiano/2015/03/1606508jovem-e-agredido-apos-discutir-com-aluna-ao-pedir-silencio-em-sala-de-aula.shtml 23/03/20I5>. Acesso em: 22 mar. 2016.

80 BERTONI, Estevão. Terceirizado, I9o tem atraso de salários e denúncias de assédio. Folha de S.Paulo, Cotidiano, I8/Io/20I5. Disponível em: http://wwwI.folha.uol.com.br/cotidiano/20I5/10/I695368-terceirizadoI90-tem-atraso-de-salarios-e-denuncias-de-assedio.shtml. Acesso em: 22 mar. 2016.

8I Disponível em < http://www.agora.uol.com.br/saopaulo/20I6/03/I752I95>-4-em-cada-Io-estudantes-jasofreram-violencia-na-escola.shtml. 2I/3/20I6>. Acesso em: 22 mar. 2016.

82 SOARES, Louise. "É bom saber que uma denúncia vai adiante neste país", diz Taís Araújo sobre prisão de responsáveis por ofensas racistas. Folha de S. Paulo, Celebridades, I8/3/20I6. Disponível em: http://f5.folha.uol. com.br/celebridades/20I6/03/IoooIoI7-e-bom-saber-que-uma-denuncia-vai-adiante-nesse-pais-diz-tais-araujosobre-prisao-de-responsaveis-por-ofensas-racistas.shtml. Acesso em: 22 mar. 2016.

83 Disponível em <http://oglobo.globo.com/sociedade/educacao/livros-escolares-perpetuam-sexismodiz-unesco-I8826859. 08/03/20I6〉. Acesso em: 22 mar. 2016.

84 FANTTI, Bruna. Religiões de raiz africana pedem investigação de grupo Gladiadores do Altar. Folha de S.Paulo, 23/3/20I5. Disponível em: <http://wwwI.folha.uol.com.br/poder/20I5/03/1607108-religioes-de-raizafricana-pedem-investigacao-de-grupo-gladiadores-do-altar.shtml. 23/03/20I5 $\rangle$. Acesso em: 22 mar. 2016. 
deveres, mas dar voz e vez a todos e a todas de maneira equacionada, garantindo-lhes também os direitos.

Para Fairclough ${ }^{85}$, as ideologias são

[...] significações/construções da realidade (o mundo físico, as relações sociais, as identidades sociais) que são construídas em várias dimensões das formas/sentidos das práticas discursivas e que contribuem para a produção, a reprodução ou a transformação das relações de dominação.

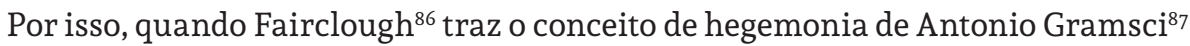
para o interior dos estudos do discurso, entendido como um equilíbrio instável, demonstra uma produtiva aliança dentro dos estudos da linguagem para repensar conceitos problemáticos e indicadores de assimetrias sociais e sustentáculo de relações desiguais e conflituosas, especialmente quando não obrigatoriamente permanece na esfera ideológica e parte de um nível discursivo de um ódio demonstrativo de uma sociedade doente para o nível comportamental.

\section{O PROBLEMA DO DISCURSO DE ÓDIO: DO UNIVERSO DO DISCURSO PARA O UNIVERSO DO COMPORTAMENTO}

Com tudo isso, parece-nos produtivo conectar os problemas relacionados a grupos minoritários e grupos vulneráveis, na sua interseção com a (in)tolerância, à ideia de discurso de ódio, pois percebemos que, num primeiro momento, é uma violência simbólica que sustenta o conceito de tolerância no sentido de suportar a diferença que nunca foi verdadeiramente acolhida. Esse não acolhimento, por sua vez, está ancorado na pressuposição de uma relação de poder à qual subjaz o pensamento de que alguém precisa aceitar o outro, por isso há registros de "aceitar" como sinônimo ou relacionado a "tolerar" em Pessek ${ }^{88}$. Nesse dicionário ${ }^{89}$, reverbera a relação das seguintes palavras interligadas: "acatar”, “aceitar”, "acolher”, “admitir”, "aprovar”, "conceder”, “concordar”, “conformar-se”, "deferir”, "engolir”, "permitir” e "topar”. Por isso, é dada vazão a conflitos e tensões entre os diversos grupos que compõem a sociedade, resultando em variados problemas originários num grupo que pretende dominar outro.

De acordo com Bourdieu ${ }^{\circ}$, há quatro formas de capital que determinam a dominação ou não sobre outros: o capital econômico, constituído pelos fatores de produção (como terra, fábrica e trabalho) e de recursos econômicos (por exemplo:

\footnotetext{
85 FAIRCLOUGH, Norman. Discurso e mudança social. Brasília: Ed. da UnB, 200I. p. II7.

86 Ibidem.

87 GRAMSCI, Antonio. Obras escolhidas. São Paulo: Martins Fontes, I978.

88 PESSEK, Kurt, op. cit., p. 33.

89 Ibidem.

90 BOURDIEU, Pierre. O poder simbólico. Lisboa: Difel, I989.
} 
renda, patrimônio e bens materiais); o capital cultural, que é formado pelo conjunto das qualificações intelectuais; o capital social, composto pela rede de relações interpessoais nas diferentes esferas da vida cotidiana; e, por último, o capital simbólico, por sua vez relacionado ao reconhecimento de um status; ou seja, trata-se do reconhecimento dos capitais anteriores e sua importância em cada campo da sociedade. Para o autor, portanto, essas formas de capital é que possuem a capacidade de estruturar o espaço social e, por isso, alguém se tornaria diferenciado, produzindo hierarquias, devido à própria desigual distribuição de capitais.

Roso et al. ${ }^{91}$ destacam que às minorias foram negadas autonomia e responsabilidade. Por essa razão, não seriam reconhecidas nos sistemas existentes de poder. Desse modo, quando um grupo minoritário deseja introduzir um elemento novo, por carecer de poder, não consegue assim fazê-lo, ou, quando tenta, é depreciado e, muitas vezes, exposto ao ridículo.

Fleury ${ }^{92}$ afirma que, no Brasil, a diversidade é definida em termos de poderio econômico e tipo de raça, e defende que outras dimensões devem ser consideradas, como gênero, pessoas portadoras de deficiência, e assim por diante.

Talvez na esteira dessa discussão é que "a noção contemporânea de minoria [...] refira-se à possibilidade de [esses grupos] terem voz ativa ou intervirem nas instâncias decisórias do Poder [..."”3.

O que levantamos como barreira é a própria estabilização de um poder que é instável, pois pode ser desafiado pelas lutas entre os grupos que se põem em contato. Entretanto, o que temos verificado é cada vez mais violências física e simbólica.

Rouquette ${ }^{44}$, abordando as condições que, segundo ele, podem ser relacionadas à manifestação da violência das massas, assevera que o ato violento tem como objeto grupos com os quais se estabelece uma relação de dominância numérica, real ou suposta. Esse autor parece atribuir o conceito de minoria a grupos (não necessariamente minoritários no sentido numérico), cujas normas passaram, num plano ético, por um processo de minorização que os coloca fora da "normalidade" 5 . Por isso, a intolerância pode ser compreendida como manifestação de algo, tal qual o preconceito, a discriminação e a violência, dentre outros.

Nesse sentido, quando a intolerância se manifesta para além da esfera discursiva, vemos episódios de violência não apenas simbólica, mas também física, como

9I ROSO, Adriane et al. Cultura e ideologia: a mídia revelando estereótipos raciais de gênero. Psicologia ef sociedade, v. I4, n. 2, p. 74-94, jul./dez. 2002.

92 FLEURY, Maria Tereza Leme. Gerenciando a diversidade cultural: experiência de empresas brasileiras. RAE - Revista de Administração de Empresas, São Paulo, v. 40, n. 3, p. I8-25, jul./set. 2000.

93 SODRÉ, Muniz, op. cit., p. I2.

94 ROUQUETTE, Michel-Louis. Massas, normas e violência. Ciência es saúde coletiva, v. 4, n. I, p. 20I-204, I999. Disponível em: 〈http://www.scielo.br/pdf/csc/v4nI/7I43.pdf 〉. Acesso em: 2 jul. 20I4.

95 Ibidem, p. 203. 
resultados de um discurso de ódio, algo que tem sido debatido tanto no universo da filosofia ${ }^{66}$ quanto no jurídico 97 .

Como afirma Glucksmann ${ }^{98}$, "o ódio nada mais é do que o resultado deteriorado da ausência de educação". Para ele, o ódio existe em escala microscópica nos indivíduos e também nas coletividades, sendo que a razão para sua existência é a vontade de destruir por destruir. Isso significa que é não apenas um discurso, mas também um sentimento inócuo e desprovido de razão de ser. Nas palavras do autor, o "ódio acusa sem saber. $\mathrm{O}$ ódio julga sem ouvir. O ódio condena a seu bel-prazer. Nada respeita e acredita encontrar-se diante de algum complô universal. Esgotado, recoberto de ressentimento, dilacera tudo com seu golpe arbitrário e poderoso. Odeio, logo existo"99.

Na sua relação com a intolerância entendida como manifestação de algo, é fruto do que Glucksmann ${ }^{\text {too }}$ chama atenção quando afirma que "o ódio ataca de fora e, simultaneamente, emerge em cada um”. Então, se ele sai da esfera ideológica e ganha o espaço comportamental na forma de violência física, é porque veio de outra relação: "se atinge não importa quem e massacra seres inocentes ao acaso, isso prova que sua ação obteve sucesso, não porque induziu a pensar, mas, ao contrário, porque impediu que se pensasse sobre ela"tor. E dessa forma, "sem lei e sem rei”, é que o ódio mostra que não possui limite geográfico, político, moral ou ideológico, no momento em que demonstra que um indivíduo ou grupo quer permanecer senhor e não escravo, mas numa construção monolítica que lhe extrai os escrúpulos ${ }^{\mathrm{To}}$.

Carcará ${ }^{103}$ assegura que, inicialmente, o discurso de ódio pode ser compreendido como "uma manifestação de pensamento que incita a violência", pois ele possui furor emocional que não pode ser combatido com a sua proibição. $\mathrm{O}$ autor dialoga com Meyer-Pflug ${ }^{\mathrm{TO} 4}$ quando esta observa que "a proibição por si só não tem o condão de impedir a existência dos discursos do ódio, pois não atinge diretamente as causas que lhe deram origem, apenas veda a exteriorização com vistas a evitar danos causados às pessoas atingidas". Sendo assim, percebemos os dois domínios de manifestação da intolerância, que seriam o da violência simbólica e o da violência física, sendo ambas ancoradas em relações de poder, isto é, no domínio ideológico que as consubstanciam,

96 Ver, por exemplo, GLUCKSMANN, André. O discurso do ódio. Rio de Janeiro: Difel, 2007.

97 Ver, por exemplo, OMMATI, José Emílio Medauar. Liberdade de expressão e discurso de ódio na Constituição de I988. Rio de Janeiro: Lumen Juris, 20I4; e CARCARÁ, Thiago Anastácio. Discurso do ódio no Brasil: elementos de ódio na sociedade e sua compreensão jurídica. Rio de Janeiro: Lumen Juris, 20I4.

98 GLUCKSMANN, André, op. cit., p. II.

99 Ibidem, p. I2.

IOo Ibidem, p. I4.

IOI Ibidem, p. I6.

I02 Ibidem, p. 28.

I03 CARCARÁ, Thiago Anastácio, op. cit., p. 75.

I04 MEYER-PFLUG, Samantha Ribeiro. Liberdade de expressão e discurso do ódio. São Paulo: Revista dos Tribunais, 2009,p. 230. 
razão pela qual apenas o conhecimento do universo de ideias que subjazem a um discurso de ódio poderia combatê-lo.

É nesse ínterim que entra em choque o discurso de ódio, visto como manifestação do pensamento, isto é, enquanto liberdade de expressão, e o atentado à dignidade humana dos grupos marginalizados, compreendidos como crimes ${ }^{\mathrm{T0} 5}$. Por isso, Sarmento ${ }^{\text {I06 }}$ postula que o discurso de ódio está mais próximo de um ataque à dignidade e aos direitos do que à participação num debate livre de opiniões.

Isso porque, em conformidade com Glucksmann ${ }^{\mathrm{Io}}$, “'Quem tem ódio' só reconhece em si e a seu redor o contágio moral que ele mesmo propaga como uma lei única e universal” [e] "A roda desses 'fatos corriqueiros' [racismos, chauvinismos, fanatismos, renascimento de agressividades], bastante cotidianos, indica a grande quantidade de chispas de fogo ocultas sob nossa frágil paz civil”ํo8.

Então, temos uma passagem, no que tange ao discurso de ódio, do universo do discurso para o universo do comportamento, pois as ideias de ódio, por si mesmas, estão carregadas de preconceito e de discriminação que incitam e fomentam a violência, muitas vezes deixando de nutrir ideias para nutrir ações odiosas que atingem especialmente os grupos minoritários e vulneráveis da sociedade, num forte atentado aos direitos humanos fundamentais. Isso pode ser corroborado pelo pequeno número dentre I7 entradas no Dicionário de política ${ }^{\text {I09 }}$ que ligam as questões de (in)tolerância a algum aspecto positivo. Figuram como positivas as relações com autodeterminação e direito à resistência, conselhos operários, cosmopolitismo, democracia e laicismo; de forma não clara ou ambivalente, com cultura política, fisiocracia, Iluminismo e liberalismo; e negativa, com despotismo, eurocomunismo, anticlericalismo, clericalismo, autoritarismo, stalinismo, comunismo e ideologia, demonstrando o aviltamento de direitos e o desrespeito que parte de um grupo que se coloca como central, dominante, em relação aos grupos minoritários e vulneráveis.

Conforme explicitam Bobbio, Matteucci e Pasquino ${ }^{\text {IIO }}$ no que tange ao pluralismo democrático observado na América contemporânea e em outras sociedades industrializadas, esse pluralismo é análogo às sociedades feudais e corporativas, uma vez que, nestas, haveria tolerância com os grupos constituídos, mas não com os indivíduos que, de alguma forma, teriam comportamento desviante das normas do grupo. Aqui, portanto, sobreleva-se uma condição de superioridade de um grupo dominante sobre o outro considerado desviante, diferente.

Como explanou Soares ${ }^{\text {III }}$, os valores que os direitos humanos procuram preservar como fundamentais levam à convicção de que o ser humano é, acima de tudo, ser digno de respeito por parte do "outro". Dessa maneira, respeitar esse outro significa

I05 Ver, especialmente, OMMATI, José Emílio Medauar, op. cit.; CARCARÁ, Thiago Anastácio, op. cit.

IO6 SARMENTO, Daniel. Livres e iguais: estudos de direito constitucional. Rio de Janeiro: Lumen Júris, 2010.

I07 GLUCKSMANN, André, op. cit., p. 35.

I08 Ibidem, p. 43-44.

I09 BOBBIO, Norberto; MATTEUCCI, Nicola; PASQUINO, Gianfranco, op. cit.

IIO Ibidem, p. I.247.

III SOARES, Ricardo Maurício Freire. Direitos fundamentais: reflexões e perspectivas. Salvador: JusPodivm, 20I4. 
compreendê-lo como coparticipante da vida histórico-social e, por consequência, sua dignidade estará em relação ao reconhecimento mútuo constituinte da base da vivência social. Ou seja, para além de qualquer construção grupal, é relevante atentarmos para o fato de que o importante é a preservação da dignidade humana, que é aviltada por qualquer tipo de violência física ou simbólica, por qualquer discurso que a propague, como o de ódio, na sua relação com a problemática da (in) tolerância.

\section{CONSIDERAÇõES FINAIS}

Tendo como base as considerações até aqui feitas, temos que os problemas relacionados aos grupos minoritários (ou minorias) e aos grupos vulneráveis estão longe de ser resolvidos a partir de questões conceituais. Em sua conexão com problemas advindos da relação com a (in)tolerância, o que se apresenta como principal necessidade é suplantar as ideias de ódio nutridas discursiva e ideologicamente como sustentáculos das diferenças na contramão da laicidade de Estado pretendida, da suposta democracia brasileira e da própria preservação da dignidade humana. Nesse sentido, cabe destacarmos o conceito de dignidade proposto por Sarlet ${ }^{\mathrm{II} 2}$ :

Temos por dignidade da pessoa humana a qualidade intrínseca e distintiva de cada ser humano que o faz merecedor do mesmo respeito e consideração por parte do Estado e da comunidade, implicando, neste sentido, um complexo de direitos e deveres fundamentais que assegurem a pessoa tanto contra todo e qualquer ato de cunho degradante e desumano, como venham a lhe garantir as condições existenciais mínimas para uma vida saudável, além de propiciar e promover sua participação ativa e corresponsável nos destinos da própria existência e da vida em comunhão com os demais seres humanos.

A partir dessa ideia, podemos observar o quão pernicioso para a sociedade é ter que suportar ou tolerar seu semelhante por qualquer motivo, pois, em sua essência e existência, de per si, a atitude que esperamos não é maior nem menor do que a do respeito que todos merecemos para uma vivência social sadia, equilibrada e harmoniosa.

II2 SARLET, Ingo Wolfgang. Dignidade da pessoa humana e direitos fundamentais na Constituição Federal de I988. 5. ed. Porto Alegre: Livraria do Advogado, 20I2., p. 62. 


\section{SOBRE O AUTOR}

CLÁUDIO MÁRCIO DO CARMO é professor associado de Linguística e Língua Portuguesa na Universidade Federal de São João del-ReiE-mail: claudius@ufsj.edu.br

\section{REFERÊNCIAS BIBLIOGRÁFICAS}

ACSELRAD, Márcio. Por uma visão crítica de minoria. Crítica cultural, v. I, n. I, jan./jun. 2006. Disponível em: 〈http://www3.unisul.br/paginas/ensino/pos/linguagem/critica/oIoI/o6.htm>. Acesso em: Io jul. 20I4.

ADORNO, Sérgio. A violência na sociedade brasileira: um painel inconcluso em uma democracia não consolidada. Sociedade er Estado, São Paulo, v. I, n. 2, p. 299-342, jul./dez. 1995.

ALMEIDA, Marco Bettine; SOARES, Alessandro da Silva. O futebol no banco dos réus: o caso da homofobia. Revista SÍNTESE Direito Desportivo, v. 3, p. 68-82, 20I4.

BOBBIO, Norberto; MATTEUCCI, Nicola; PASQUINO, Gianfranco. Dicionário de política. Brasília: Ed. da $\mathrm{UnB}, \mathrm{I} 998$.

BOURDIEU, Pierre. O poder simbólico. Lisboa: Difel, I989.

BIDERMAN, M. T. C. As ciências do léxico. In: OLIVEIRA, A. M. P. P.; ISQUERDO, A. N. As ciências do léxico: lexicologia, lexicografia, terminologia. Campo Grande: UFMS, 200I. p. I3-22.

CALDAS AULETE. Lisboa, Portugal: E. Pinto Barto; Rio de janeiro, Brasil: Delta, I980.

CARCARÁ, Thiago Anastácio. Discurso do ódio no Brasil: elementos de ódio na sociedade e sua compreensão jurídica. Rio de Janeiro: Lumen Juris, 20I4.

CARVALHEIRO, José Ricardo. Da representação mediática à recepção política. Discursos de uma minoria. Sociologia, problemas e práticas, n. 5I, p. 73-93. 2006. Disponível em: <http://www.scielo.oces.mctes.pt/ pdf/spp/n5I/n5Ia05.pdf >. Acesso em: 2 jul. 20I4.

CERVI, Thales de Almeida Nogueira. Intolerância e racismo no futebol: a racialização do outro. ComCiência, Campinas: Unicamp, v. I59, p. IO-I6, 20I4.

CUNHA, Antônio Geraldo da. Dicionário etimológico Nova Fronteira da língua portuguesa. Rio de Janeiro: Nova Fronteira, I982.

DICIONÁRIO BRASILEIRO DA LÍNGUA PORTUGUESA. São Paulo: Mirador Internacional, I975. DICIONÁRIO DA LÍNGUA PORTUGUÊSA - dicionário do povo. 34. ed. Rio de Janeiro: F. Alves, I9--.

FAIRCLOUGH, Norman. Discurso e mudança social. Brasília: Ed. da UnB, 2001.

FERREIRA, Aurélio Buarque de Holanda. Novo dicionário Aurélio da língua portuguesa. Curitiba: Positivo, 2009.

FLEURY, Maria Tereza Leme. Gerenciando a diversidade cultural: experiência de empresas brasileiras. RAE - Revista de Administração de Empresas, São Paulo, v. 40, n. 3, p. I8-25, jul./set. 2000.

FONTINHA, Rodrigo. Novo dicionário etimológico da Língua Portuguesa. Porto: Domingos Barreira, s.d. GLUCKSMANN, André. O discurso do ódio. Rio de Janeiro: Difel, 2007. GRAMSCI, Antonio. Obras escolhidas. São Paulo: Martins Fontes, I978. HOUAISS DA LINGUA PORTUGUESA. Rio de Janeiro: Objetiva, 2007. 
LOCKE, John. Carta acerca da tolerância. São Paulo: Abril Cultural, I978.

LOPES, Aline Luciane; CORREAA, Darcísio. O multiculturalismo e os direitos fundamentais dos povos indígenas: a luta pela igualdade no Brasil da intolerância. Rev. Ciên. Jur. e Soc. da Unipar. Umuarama, v. II, n. 2, p. 47I-489, jul./dez. 2008.

MACHADO, José Pedro. Dicionário etimológico da língua portuguesa: com a mais antiga documentação escrita e conhecida de muitos dos vocábulos estudados. Lisboa: Confluência, I952-I959.

MEYER-PFLUG, Samantha Ribeiro. Liberdade de expressão e discurso do ódio. São Paulo: Revista dos Tribunais, 2009.

MICHAELIS: moderno dicionário da língua portuguesa. São Paulo: Melhoramentos, I998.

MONTE, Izadora Xavier do. A violência contra a mulher no discurso diplomático brasileiro. Boletim Meridiano 47, Brasília: UnB, v. I2, p. 36-4I, 20 II.

MONTESQUIEU, Charles-Louis de Secondat. O espírito das leis. Curitiba: Juruá, 2005.

NASCENTES, Antenor. Dicionário Etimológico da língua portuguêsa. Rio de Janeiro: F. Alves, I932.

OMMATI, José Emílio Medauar. Liberdade de expressão e discurso de ódio na Constituição de I988. Rio de Janeiro: Lumen Juris, 20I4.

PESSEK, Kurt. Dicionário de palavras interligadas, analógico e de ideias afins. Brasília: Thesaurus, 2010.

PINTO, Luiz Maria da Silva. Dicionário da língua brasileira. Ouro Preto: Typografia de Silva, I832.

REZENDE, Antônio Martinez da; BIANCHET, Sandra Braga. Dicionário do latim essencial. Belo Horizonte: Crisálida/Autêntica, 2005.

RIFIOTIS, Theophilos. Nos campos da violência: diferença e positividade. 2006. Disponível em: <http:// www.cfh.ufsc.br/ levis/downloads/artigos/NCVDP.pdf 〉. Acesso em: 2 jul. 2014.

ROGERS, Wendy; BALLANTYNE, Angela. Populações especiais: vulnerabilidade e proteção. RECIIS - $R$. Eletr. de Com. Inf. Inov. Saúde, Rio de Janeiro, v.2, p. 3I-4I, dez. 2008.

ROSO, Adriane et al. Cultura e ideologia: a mídia revelando estereótipos raciais de gênero. Psicologia esociedade, v. I4, n. 2, p. 74-94, jul./dez. 2002.

ROUQUETTE, Michel-Louis. Massas, normas e violência. Ciência e saúde coletiva, v. 4, n. I, p. 20I-204, I999. Disponível em: 〈http://www.scielo.br/pdf/csc/v4nI/7I43.pdf〉. Acesso em: 2 jul. 20I4.

SARLET, Ingo Wolfgang. Dignidade da pessoa humana e direitos fundamentais na Constituição Federal de I988. 5. ed. Porto Alegre: Livraria do Advogado, 2012.

SARMENTO, Daniel. Livres e iguais: estudos de direito constitucional. Rio de Janeiro: Lumen Júris, 2010. SÉGUIN, Elida. Minorias e grupos vulneráveis: uma abordagem jurídica. Rio de Janeiro: Forense, 2002.

SILVA, Vagner Gonçalves da (Org.). Intolerância religiosa: impactos do neopentecostalismo no campo religioso afro-brasileiro. São Paulo: Edusp, 2007.

SOARES, Ricardo Maurício Freire. Direitos fundamentais: reflexões e perspectivas. Salvador: JusPodivm, 20I4.

SODRÉ, Muniz. Por um conceito de minoria. In: PAIVA, Raquel; BARBALHO, Alexandre (Org.). Comunicação e cultura das minorias. São Paulo: Paulus, 2005. p. II-I4.

STOUFFER, Samuel Andrew. Communism, Conformity and Civil Liberties: a cross section of the nation speaks its mind. New York: Doubleday, I955.

SULLIVAN, John; PIERESON, James; MARCUS, George. Political tolerance and american democracy. Chicago: University of Chicago Press, I982.

VOLTAIRE, François Marie Arouet. Tratado sobre a tolerância. São Paulo: Escala, 2000.

ZALUAR, Alba Maria. Gangues, galeras e quadrilhas: globalização, juventude e violência. In: VIANNA, Hermano. (Org.). Galeras cariocas: territórios de conflitos e encontros culturais. Rio de Janeiro: Ed. da UFRJ, I997. p. I7-57. 
. Desafios para o ensino básico na visão dos vulneráveis. Sociologias, Porto Alegre, v. I, p. 228-249, I999. . Exclusion and public policies: theoretical dilemmas and political alternatives. Revista Brasileira de Ciências Sociais, v. I, p. 25-42, 2000.

. Violence in Rio de Janeiro: styles of leisure, drug use, and trafficking. International Social Science Journal, Londres and Paris, Unesco, v. LIII, n. 3, p. 369-379, 2001. 